\title{
Research on Tourism Satisfaction Improvement Under the Background of the Belt and Road Initiative: A Case Study of Zhanjiang
}

\author{
Weidong Lai ${ }^{1,2}$, Zhaoxi Deng ${ }^{3}$ \\ ${ }^{1}$ School of Business, Lingnan Normal University, Zhanjiang, China \\ ${ }^{2}$ Guangdong Coastal Economic Belt Development Research Center, Zhanjiang, China \\ ${ }^{3}$ Finance Department, Zhanjiang Preschool Education College, Zhanjiang, China
}

Email address:

natureeast@139.com (Weidong Lai),366861668@qq.com (Zhaoxi Deng)

To cite this article:

Weidong Lai, Zhaoxi Deng. Research on Tourism Satisfaction Improvement Under the Background of the Belt and Road Initiative: A Case Study of Zhanjiang. Journal of Business and Economic Development. Vol. 4, No. 4, 2019, pp. 142-148. doi: 10.11648/j.jbed.20190404.13

Received: October 27, 2019; Accepted: November 21, 2019; Published: December 2, 2019

\begin{abstract}
Under the promotion and guidance of the national "Belt and Road Initiative", tourism has become one of the important ways for communication between countries along the "Belt and Road". It is a bridge connecting the economic development of cities in various countries. Zhanjiang is one of the first "One Belt, One Road" maritime cooperation fulcrum cities. It is the central city of North-Gulf City and has the reputation of "China Excellent Tourism City" and "Charming City with Chinese Characteristics". Based on the five aspects of "eat, live, travel, sightseeing and purchase", this paper collects the satisfaction data of Zhanjiang tourism by questionnaire survey, and uses IPA analysis method to analyze the tourism satisfaction of Zhanjiang. According to the analysis, the tourism satisfaction of Zhanjiang is relatively good, but there are still some places with low satisfaction, mainly in the areas of convenient transportation, catering service quality, scenic project and scenic facilities. Therefore, the author analyzes the importance and satisfaction of each quadrant, analyzes the causes of the differences according to the degree of distribution, and finally proposes targeted improvement measures for different factors and different importance-satisfaction to improve tourism satisfaction of Zhanjiang. So as to realize the healthy development of Zhanjiang tourism, and finally realize the effective improvement of Zhanjiang's economy.
\end{abstract}

Keywords: Tourism Satisfaction, Questionnaire Survey, IPA

\section{Introduction}

With the development of society, people's living standards are getting higher and higher. Tourism has become an indispensable part of people's lives. According to the report of the 19th National Congress, tourism in the new era is not simply providing traditional tourism services. It should be a green, enriching and poverty alleviation industry. At the same time, under the promotion and guidance of the national "Belt and Road" initiative, tourism has become one of the important ways for communication between countries along the "Belt and Road" and along the line, and is a bridge connecting the economic development of cities and cities. Tourism has attracted more and more people's attention, and the demand for improving the quality of tourism is even more demanding [1].

Zhanjiang is one of the first "One Belt, One Road" maritime cooperation fulcrum cities. It is the central city of North Gulf City and has the reputation of "China Excellent Tourism City" and "Charming City with Chinese Characteristics". The tourism industry in Zhanjiang started relatively early, which depends on Zhanjiang's rich human resources and natural resources. In recent years, the Zhanjiang Municipal Government's work report, the "Guangdong Province Coastal Tourism Development Plan" and the "Guangdong Province Participation in the Construction of the "Belt and Road" Implementation Plan" have repeatedly mentioned the need to actively develop the tourism industry cluster centered on Zhanjiang. Construction of the North Gulf tourist circle with distinctive features.

As an important indicator to measure the quality of tourism services, tourism satisfaction can effectively reflect the current situation of tourism market development and possible 
problems. The IPA analysis method has been mature in the field of tourism. Through the combination of IPA analysis and tourism satisfaction, from the two aspects of satisfaction and importance, it analyzes the indicators that need to be improved and improved in the tourism development process [2]. And points out specific recommendations for each influencing factor. Use these specific recommendations to improve the overall level of tourism satisfaction, realize the healthy development of Zhanjiang tourism, and finally realize the effective improvement of Zhanjiang economy.

\section{Research Theory}

At present, the research on satisfaction has been applied to all walks of life, especially the service industry, and it is possible to find problems and solve problems more directly through research satisfaction. As early as the 1970s, foreign countries began to study tourist satisfaction. The famous scholar Pizam (1978) first proposed the concept of tourist satisfaction. He pointed out that tourist satisfaction is a kind of pleasure or disappointment feeling state after the tourists compare the perception of the tourist destination with the expectations set by himself. Whipple (1988) pointed out that tourists will be affected by the "halo effect". If a tourist is dissatisfied with a project or service, the tourist will be dissatisfied with the entire tourism project or service.

When foreign scholars' research on customer satisfaction is in full swing, many scholars in China have begun to explore and research foreign satisfaction research theory and its application and development in China. Fang Wei (2016) believes that customer satisfaction is directly related to the actual perception of customers, and it is necessary to continuously satisfy the diverse and differentiated tourism needs of tourists [3]. Wang Yini (2017) takes the ecological civilization as the perspective and satisfies the tourists' demand for tourism by developing eco-tourism, thus promoting the sustainable development of tourism [4]. Li Yuli and Li Yang (2016) combined the fuzzy comprehensive evaluation model with the Likert scale to study the satisfaction of tourists in Hanzhong [5]. Wang Qiu Na (2019) is based on the perspective of rural tourism. It mainly uses various indicators that affect the satisfaction of rural tourism travelers as the research direction, and builds a satisfaction assessment model with rural characteristics [6]. Shen Weili, Wang Wanyun (2019) Using IPA analysis method to analyze the importance and satisfaction of Lianyungang tourism public service, find out the gap and propose strategies [7].

From the research on tourism satisfaction at home and abroad, it mainly focuses on the research of the satisfaction of employees in the tourism industry and the satisfaction of tourists. As a coastal tourist city, there are few studies on Zhanjiang tourism satisfaction. The 19th National Congress clearly wrote the "Belt and Road" construction into the party constitution, which shows China's determination and confidence in promoting the "Belt and Road" construction. In the context of "Belt and Road", this paper takes Zhanjiang tourism satisfaction as the research object, and analyzes the tourism satisfaction to find out the factors that influence or restrict the development of Zhanjiang tourism industry. Combine the characteristics of Zhanjiang's tourism industry development with satisfaction, and collect the relevant satisfaction data in the form of a questionnaire. Using IPA analysis + SPSS data analysis software, the customer's importance perception and satisfaction perception are combined to show four areas, such as the advantageous area (continue to maintain the hard work area), the holding area (without deliberate pursuit of the area), the improvement area (low priority processing area), and the weak area (key improvement area) Out of the four areas, such as the advantageous area (continue to maintain the hard work area), the maintenance area (without deliberate pursuit of the area), the improvement area (low priority processing area), and the weak area (key improvement area) [8]. And then propose corresponding countermeasures according to different areas. It is recommended to promote the development of Zhanjiang's tourism industry towards diversification, high quality and sustainable development.

\section{Methodology and Analysis}

\subsection{Methodology}

\subsubsection{IPA Analysis}

IPA (Importance Performance Analysis), the principle is: customer satisfaction with a product or service is related to the customer's level of concern or importance. It is used to represent the customer Satisfaction and importance to the product or service. IPA takes the importance as the $\mathrm{X}$-axis (horizontal axis) and the satisfaction as the Y-axis (vertical axis), and divides it into four quadrants centering on the average of importance and satisfaction. Using questionnaires to collect data, the indicators of importance and satisfaction are mapped into four quadrants. By analyzing the location of each indicator, the importance and satisfaction level are judged. In addition, the reasons for the differences are analyzed according to the degree of distribution. Finally, different improvement strategies are proposed for different importance-satisfaction. IPA analysis is intuitive and easy to judge, and is widely used in various service areas [9].

\subsubsection{Questionnaire}

The questionnaire is a kind of carrier that the investigator directly presents the research questions to the respondents who participated in the questionnaire through paper materials or electronic materials. And records the opinions of the respondents on the questions, so as to obtain the corresponding information and materials [10].

The design of the questionnaire should be combined with the principle of probability and statistics. Therefore, in addition to paying attention to the professional level of the investigator, the selection of the sample, and the research and analysis tools, questionnaire design is also a prerequisite and important basis for the questionnaire analysis.

This study used a questionnaire to collect the tourist satisfaction data. This questionnaire consists of three parts: the 
beginning part, the main part and the ending part. The beginning part includes the greeting, the purpose and significance of the survey, also includes a thank-you to the respondents and the notes on the final notes. The main part includes relevant indicators of tourism satisfaction in Zhanjiang. According to the research needs, a total of 18 measurement variables from the five aspects of "eat, live, travel, sightseeing, purchase" are used for analysis. In addition, the Likert scale is used to quantify the questionnaire. The degree of satisfaction is expressed as "very satisfied, satisfied, general (unsure), dissatisfied, very dissatisfied", and the degree of importance is expressed as "very important, important, general (uncertain), unimportant, very unimportant". Use 5, 4, 3, 2, 1 points to represent the score. At the ending part, fill in the customer's relevant information, including the customer's gender, age, education level, occupation, monthly average salary, travel mode, etc.

\subsection{Data Analysis}

\subsubsection{Data Sources}

This time chooses eight scenic spots in Zhanjiang as the research site: East Island, Huguangyan, Sea promenade, Jinqiao Park, Pazhou Ancient Rhyme-Weizhou Island, South Asian Tropical Botanical Garden, Nansan Island, Zhanjiang Port and so on. In order to investigate the comprehensiveness and effectiveness of the data, a total of 750 questionnaires were distributed, 750 copies were recovered. Among them, there were 738 valid questionnaires with an effective rate of $98.4 \%$. At the same time, the reliability analysis of 738 valid questionnaires was carried out. In this paper, the Cronbach $\alpha$ reliability coefficient method is used, and the reliability analysis of 738 valid questionnaires is carried out by SPSS statistical analysis software. Firstly, the 738 valid questionnaires collected will be entered into the system. According to the analysis of SPSS statistical software, the Cronbach $\alpha$ reliability coefficient was 0.861 , and the Cronbach $\alpha$ was greater than 0.8 . Through analysis, it can be concluded that the questionnaire has reliability and reference value, which can be further studied.

\subsubsection{Comparative Analysis of Tourists' Importance and Satisfaction}

This survey mainly collects and analyzes data from 18 indicators: "eat, live, travel, sightseeing and purchase". It can be seen from Figure 1 that the highest tourist satisfaction is "live", the satisfaction is 4.17 , followed by "purchase" (4.02), "sightseeing" (3.78), and "eat" (3.72), while "travel" has the lowest satisfaction of 3.32. Among them, "sightseeing", "eat", and "travel" are below average, indicating that there may be more problems in these areas, and it is necessary to focus on and improve. In addition, the importance of "sightseeing" is the highest among visitors, which is 4.50 , followed by "eat" (4.17), "travel" (3.99), and "purchase" (3.89), while tourists have relatively few requirements for "live". The minimum level is 3.67 .

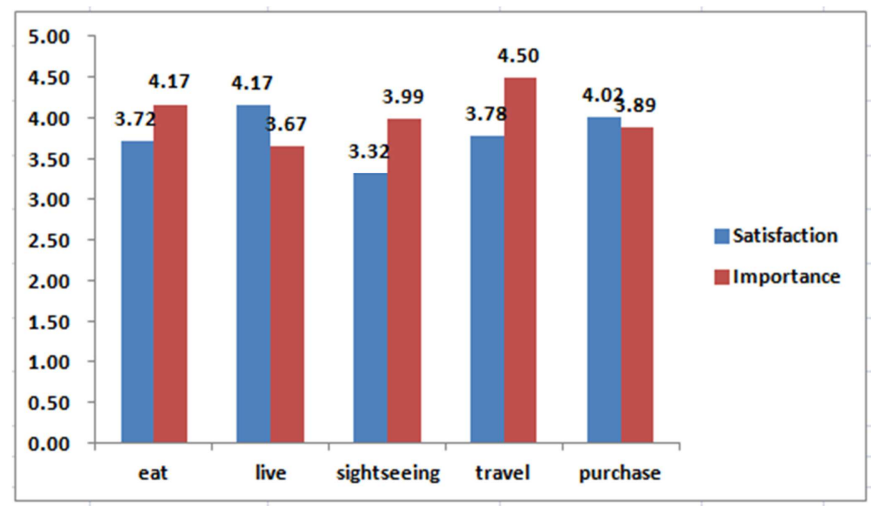

Figure 1. Comparative analysis of the importance and satisfaction of tourists (overall).

A detailed comparative analysis of the satisfaction and importance of the 18 measurement variables in the five aspects of "eat, live, travel, sightseeing and purchase" is helpful to find out the factors which affect the satisfaction of tourists. According to the problem, targeted solution are proposed to enhance the satisfaction of tourists. The specific data is as shown in Table 1.

Table 1. Comparative analysis of tourists' importance and satisfaction (detailed).

\begin{tabular}{|c|c|c|c|c|}
\hline Type & Measurement standard & Importance & Satisfaction & Gap \\
\hline \multirow{4}{*}{ Eat } & Eating environment sanitation & 3.24 & 3.67 & -0.43 \\
\hline & The quality of catering services & 4.31 & 3.17 & 1.14 \\
\hline & The richness of food and beverage & 4.65 & 4.16 & 0.49 \\
\hline & The reasonable price of food and beverage & 4.48 & 3.87 & 0.61 \\
\hline \multirow{4}{*}{ Live } & The sanitation of accommodation & 4.39 & 4.15 & 0.24 \\
\hline & Accommodation service quality & 3.64 & 3.91 & -0.27 \\
\hline & Accommodation facilities & 3.21 & 4.25 & -1.04 \\
\hline & Reasonable accommodation prices & 3.42 & 4.35 & -0.93 \\
\hline \multirow{3}{*}{ Travel } & Convenient intercity transportation & 3.68 & 3.28 & 0.4 \\
\hline & City line arrangements & 4.26 & 3.39 & 0.87 \\
\hline & Reasonable transportation & 4.02 & 3.29 & 0.73 \\
\hline \multirow{4}{*}{ Sightseeing } & The sanitation of scenic spots & 4.53 & 4.26 & 0.27 \\
\hline & The abundance of scenic spots & 4.21 & 3.65 & 0.56 \\
\hline & Public facilities in the sights & 4.51 & 3.27 & 1.24 \\
\hline & The reasonable price of tickets & 4.73 & 3.95 & 0.78 \\
\hline \multirow{3}{*}{ Purchase } & Shopping environment & 3.37 & 3.65 & -0.28 \\
\hline & Rich shopping variety & 3.98 & 4.21 & -0.23 \\
\hline & The reasonable shopping price & 4.31 & 4.19 & 0.12 \\
\hline
\end{tabular}


It can be seen from Table 1 that the top three items with the highest satisfaction are the accommodation facilities, the reasonable accommodation price, the sanitation of the scenic spots, and the lowest satisfaction are: the quality of catering services, convenient intercity transportation, and public facilities in the sights. This indicates that tourists are more satisfied with the accommodation conditions in Zhanjiang, but the quality of service, the convenience of transportation and the layout of attractions need to be strengthened. The top three items of importance are: the richness of food and beverage, the sanitation of scenic spots, the reasonable price of tickets, and the three lowest items: eating environment sanitation, accommodation facilities, and shopping environment. This indicates that tourists pay more attention to the richness of food, the health of scenic spots, and the price level of each scenic spot. The more attention tourists pay, the more important it is to improve and satisfy the needs of tourists.

\subsubsection{IPA Model Analysis}

It can be seen from Table 1 that there is a big difference in the importance perception and satisfaction of tourists, so IPA analysis can effectively reflect the relationship between them. The importance is taken as the $\mathrm{X}$-axis, and the satisfaction is taken as the Y-axis (vertical axis). The quadrant is divided into four quadrants which Centered on the average of importance and satisfaction. Based on the data of questionnaires, 18 measured variables were marked into four quadrants, as shown in Figure 2.

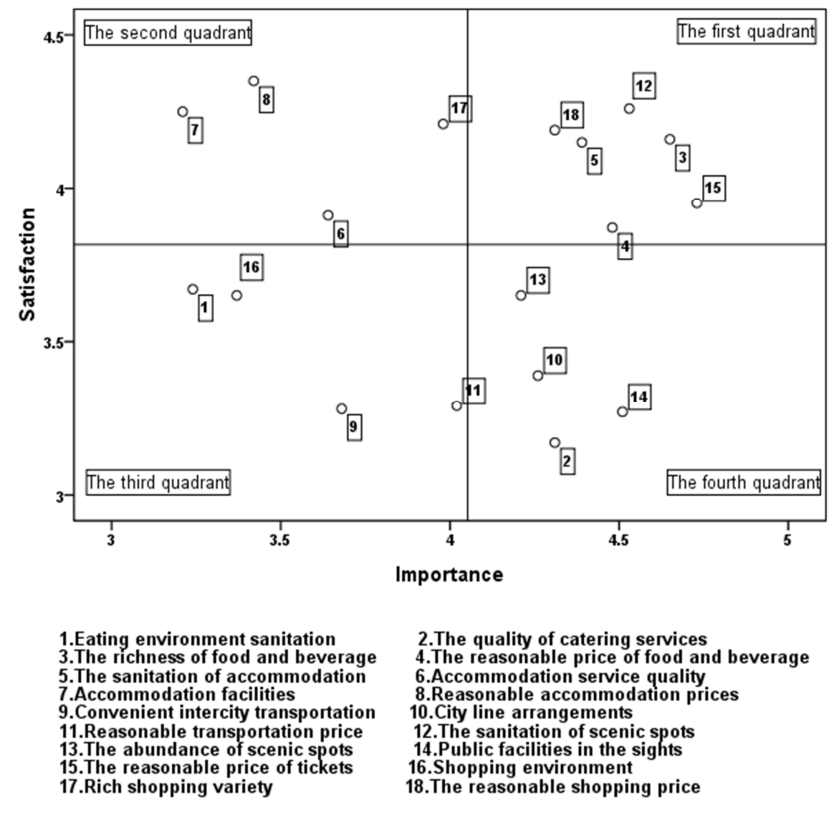

Figure 2. Tourism Satisfaction IPA Chart.

The first quadrant: high importance and satisfaction, is the advantage zone. In the first quadrant, there are 6 measurement indicators, which are the richness of food and beverage, the reasonable price of food and beverage, the sanitation of accommodation, the sanitation of scenic spots, the reasonable price of tickets, and the reasonable shopping price. From the analysis of IPA chart, it can be concluded that tourists pay more attention to price and accommodation and scenic environment, and their satisfaction is relatively high. This depends on the achievements of Zhanjiang tourism city development planning. Zhanjiang has the reputation of "China's Excellent Tourism City" and "Charming City with Chinese Characteristics". At the same time, with the opportunity of "One Belt, One Road" development [11], it constantly develops and perfects the beauty of "playing in Zhanjiang, eating in Zhanjiang, watching the mountains and watching the sea in Zhanjiang".

The second quadrant: low importance but high satisfaction, is the holding area. It includes four indicators: accommodation service quality, accommodation facilities, reasonable accommodation prices, and rich shopping variety. From the analysis principle of IPA, the measurement index of the second quadrant is less important than the index of the first quadrant, but the satisfaction of tourists shows high, which also increases the overall level of tourism satisfaction in Zhanjiang. To an important role, it will continue to be maintained in the future development. As can be seen from Figure 2, tourists' attention to "residence" is declining, and it has not become a major factor in the quality of accommodation, facilities and prices. It depends on the rapid development of China's hotel industry and the rise of various specialties. In addition, tourists are more satisfied with the variety of shopping.

The third quadrant: low importance and satisfaction, is a weak improvement zone. It includes four indicators: eating environment sanitation, reasonable transportation price, convenient intercity transportation, and shopping environment. From the analysis principle of IPA, tourists do not pay much attention to the indicators of the third quadrant, and they are also dissatisfied with these indicators. The dissatisfaction of tourists will affect the overall tourism satisfaction, so it still needs to be improved. Such as the dining environment, transportation prices, shopping environment, attractions and other facilities are not enhanced, long-term past will affect the tourists' perception of "eat, live, travel, sightseeing, purchase" and so on.

The fourth quadrant: high importance but low satisfaction, focusing on improvement areas. Including the quality of catering services, city line arrangements, public facilities in the sights, and the abundance of scenic spots. From the analysis principle of IPA, the indicators of the fourth quadrant are of high importance, tourists pay attention to it, but the perception of satisfaction is poor, which is an urgent need to strengthen the improvement. For example, the quality of service is an indicator that directly displays the image of Zhanjiang, and should be strengthened. The convenience of transportation and the richness of scenic spots are also directly affecting the perception of tourists' development of the city, and need to improve and improve first. 


\section{Zhanjiang Tourism Satisfaction Enhancement Strategy}

From the above IPA analysis results, Zhanjiang's overall satisfaction with tourism satisfaction is better, but there are still many areas for improvement.

\section{1. "Hunger Breeds Discontentment", Create the Food Capital of Zhanjiang}

Zhanjiang is known as "the capital of Chinese seafood cuisine", and a large part of the tourists coming to Zhanjiang is running Zhanjiang's delicious seafood. Therefore, the catering service is essential, it directly affects the perception of Zhanjiang.

First, from the above IPA chart, it can be seen that the satisfaction of "food service quality" and "dining environment sanitation" is low, and important improvements are needed. Zhanjiang is a city with many dialects. The most typical dialect is Leizhou dialect which the locals call it Lihua. The Cantonese is second, and the Hakka is third. To improve service quality, we must first start with language expression and give priority to Mandarin. Let friends who come in all directions can clearly feel the warm hospitality of the people of Zhanjiang. Secondly, improve the overall quality of catering service personnel. Strengthen training, including the grooming of service personnel, service language specifications, etc., and continuously strengthen the service standards of service personnel in daily work. Through training, the service level of the salesperson is effectively improved, and the basic conditions for providing good customer service work are provided. Thirdly, strengthen inspection and supervision of the catering industry. Ensure that the catering industry must meet the hygiene standards of the catering industry, and each functional area such as food processing area cooking area, and sanitary area should be rationally arranged, and tableware that meets food safety standards should be provided. Relevant departments shall conduct inspections on a regular or irregular basis. If violations of laws and regulations are found, they shall be urged to rectify them, and shall be seriously investigated and punished according to law. Information such as daily sampling inspections and punishments shall be disclosed to the public in a timely manner.

Second, the satisfaction of "food richness" and "reasonable food and beverage prices" is high, and we must continue to maintain and strive for greater improvement [12]. In 2017, "Charming Chinatown", the 12th food in Zhanjiang detonated the audience. " In January, Pomfret is very tender; in February, Oyster is fat; in March, the lobster is fat and strong; in April, the squid is sweet; in May, the sea bream is really delicious; in June, Ling is delicious too; in July, the abalone is fat; in August, grouper is precious; in September, butter crab is the best; in October, Spanish mackerel is fragrant; in November, eel is very good; in December, sandworm is the most plump" has deep into people's hearts. Zhanjiang people can make use of local high-quality ingredients to make a variety of dishes suitable for guests from all directions, and to operate in good faith, clearly priced, and fair prices to attract more tourists to taste.

\subsection{Improve the Quality of Accommodation and Create a General Feeling}

Zhanjiang has the reputation of "China's Excellent Tourism City". The development of tourism cities is inseparable from the hotel services that are compatible with it. According to the analysis of the survey data, tourists' attention to "residence" is declining, and it has not become the focus of attention in terms of service quality, supporting facilities and price of accommodation. Tourists are more satisfied with "residence". It depends on the rapid development of China's hotel industry and the rise of various specialties.

Zhanjiang has a number of five-star, four-star, three-star hotels to meet the needs of different tourists. In the future management, we must continue to maintain. The management department should strengthen the supervision of the hotel industry, and the hotel industry should continue to improve its service level, create a hotel brand with Zhanjiang characteristics, attract more visitors to experience. In addition, the hotel industry can also create some theme hotels with Zhanjiang characteristics, such as the cultural elements of Zhanjiang, to provide more choices for tourists [13].

\subsection{Strengthen Traffic Road Planning and Build a "Belt and Road" Channel}

Zhanjiang is one of the first "One Belt and One Road" maritime cooperation fulcrum cities. It is the central city of the western Guangdong and North Gulf urban agglomerations. The development and improvement of Zhanjiang traffic will help promote the development of the economy along the line and promote the development of tourism in Zhanjiang [14].

First, from the above IPA chart, it can be seen that the "city line arrangement" has low satisfaction, which affects the overall level of tourism satisfaction. Zhanjiang has 4 municipal districts, 3 county-level cities, and 2 counties. Each special scenic spot is distributed in various regions, and the activities between the scenic spots must pass through various regions. Therefore, we must first standardize the city's traffic signs, especially the indications of various special attractions, to facilitate the tourists to easily find the route within the city, and to rationally plan the itinerary. In addition, the traffic law enforcement department should strengthen the control of traffic roads, severely punish and stop the chaos. By speeding up the flow of roads, visitors can play safely and smoothly.

Second, the satisfaction of "intercity transportation convenience" and "reasonable transportation price" is relatively high. Mainly in the intercity traffic, after the opening of the Jiangzhan Railway in July 2018, the time from Zhanjiang to the Pearl River Delta was shortened to about 3 hours, and the time was greatly shortened. Zhanjiang also officially entered the "high-speed rail era." [15] In addition, the inter-city transportation of Zhanjiang has a variety of transportation modes such as roads, railways, airplanes, 
waterways, etc., so that tourists can choose the appropriate way to travel according to their own needs. In terms of transportation prices, tourists' attention is not high, but overall satisfaction is high. Therefore, relevant government departments need to continue to pay attention to the people's voice, people's hearts and reasonable pricing in the future. Traffic law enforcement departments should increase punishment for illegal operations such as black cars, regulate the taxi and drip truck markets, and make transportation more convenient, safer and more beneficial to the people.

\subsection{Improve Scenic Facilities and Enrich Scenic Spots}

Tourist attractions are an important part of the tourism industry. They can meet the needs of tourists for leisure, recreation, relaxation, and so on. They are an important factor in attracting and retaining tourists.

First, it can be concluded from the IPA chart that the two indicators of "public facilities in the sights" and "the abundance of scenic spots" are low in satisfaction, which cannot effectively attract tourists, and is not conducive to promoting tourists' second visits. Therefore, detailed and accurate signs should be set up in the scenic spot, and tour guides should be provided. Appropriate rest areas should be added to facilitate the tourists to rest during the play. in addition, increase the number of public toilets and solve the problem of waiting in the queue [16]. Regarding the play items, cultural projects with Zhanjiang characteristics can be added to the scenic spots. Zhanjiang has a number of intangible cultural heritages, such as "Wuchuan Floating Color", "East Island People-Dragon Dance", "Xunxi Lion Dance", etc.. The combination of special features and cultural projects creates a tourism brand with Zhanjiang characteristics, which effectively attracts tourists' sightseeing experience and enhances tourists' satisfaction and loyalty $[17,18]$.

Second, the two indicators of "environmental sanitation of scenic spots" and "reasonable ticket prices" are highly satisfied and need to continue to maintain this advantage. Especially in terms of environmental sanitation, we will add some environmental protection slogans throughout the scenic spots to remind visitors to pay attention to maintaining environmental sanitation. At the same time, all garbage bins in the scenic spots should be promptly sent to clean up, especially during the tourist season. The ticketing of scenic spots establishes a standardization mechanism, and the price cannot be adjusted at will, which affects the perception of customers [19].

\subsection{Improve the Shopping Environment and Improve Economic Efficiency}

To improve the environment of shopping places, we must first do a good job in the management of mobile traders, and stop the act of chaos and selling fake and shoddy goods. The urban management law enforcement department should strengthen inspections and timely find rectification. Contact management with the urban management law enforcement department, consumer maintenance associations, and the merchant. So as to create a harmonious shopping environment.

Satisfaction is high in variety and price, but efforts are still needed to continue to ensure the variety and quality of various handicrafts, seafood, and other Zhanjiang specialties. At the same time, according to the needs of tourists, we provide all kinds of packaging, joint express delivery companies, assist in mailing all kinds of products for tourists. Do a good job in after-sales service, maintain and enhance the satisfaction of tourists, thereby improving the economic efficiency of Zhanjiang.

\section{Conclusion}

With the development of the economy and the improvement of people's lives, tourism has become a continuous demand. The development of tourism is not only to meet people's basic needs for tourism, but to provide high-quality tourism services. Under the promotion and guidance of the national "Belt and Road" strategy, with the good momentum of Zhanjiang's economic development, improve the service quality of all levels of Zhanjiang tourism, improve the tourism satisfaction of Zhanjiang, enhance the competitiveness of Zhanjiang tourism, and promote the healthy and sustainable development of tourism in the North Gulf Economic Zone with Zhanjiang as the core.

\section{Acknowledgements}

This paper was supported by 2019 Guangdong Coastal Economic Belt Development Research Center (Grant Number: 20193L02).

\section{References}

[1] Gao Yuli. The Belt and Road Construction and Tourism First [N]. 2015, 12 (B01).

[2] Chen Yumei. Research on the Improvement of Coastal Tourism Satisfaction Based on IPA Analysis_- Taking Xiamen as an Example [J]. Journal of Jiangxi Science and Technology Normal University, 2018, No. 181 (03): 68-75.

[3] FANG Wei, WANG Lili, XU Yaling. Research on Influencing Factors of Tourist Ecotourism Satisfaction [J]. Business research, 2016, 62 (11): 168-176.

[4] Wang Yini, Song Xinzhe, Liu Wei. Research on Island Tourism Satisfaction Based on the Perspective of Ecological Civilization_- Taking Changhai County as an Example [J]. Studies in Terrestrial and Natural Resources, 2017 (5), 61-65.

[5] Li Yuli, Li Yang. Research on Tourism Satisfaction Evaluation in Hanzhong Based on Fuzzy Comprehensive Evaluation [J]. Value Engineering (2), 2016,: 24-27, total 4 pages.

[6] Wang Qiu Na. Research on Rural Tourists' Satisfaction Based on IPA Analysis_ _ Taking Zhongliao Village in Sanya as an Example [J]. Vacation tourism, 2019 (2).

[7] Shen Weili, Wang Wanyun. Research on Tourist Satisfaction of Lianyungang Tourism Public Service Based on IPA Analysis [J]. Journal of Huaiyin Teachers College (Philosophy and Social Sciences), 2019 (3). 
[8] Gao Zhiyang. The application of IPA analysis in the field of domestic tourism research. Exam weekly. Issue 40, 2012.

[9] Xu Changting. Research on Tourist Satisfaction of Tourist Resorts Based on IPA Model [D]. Shanghai Normal University, 2012.

[10] Zhang Shiyu, Questionnaire Data Analysis Practice [Monograph]: Capital University of Economics and Business Press, 2015.

[11] Zou Yongguang. The Economic Linkage of "One Belt, One Road" Tourism in China's Major Node Cities_- Space Structure and Cooperation Pattern [J]. Economic Management, 2017 (5): 24-37.

[12] Wu Xianxia, Qin Xiaoli, Yan Min. Personality Characteristics of Tourist Destinations and Tourist Loyalty_-Taking Tourist Satisfaction as Mediator [J]. Journal of Hunan Finance and Economics College, 2017 (6).

[13] Wang Jiangzhe. A comparative study on the relationship between tourism tourists and holiday tourists in local attachment, satisfaction and loyalty [D]. Shandong University, 2016.
[14] Zhu Chang. Research on Tourist Satisfaction Survey of Tourism Traffic Service in Henan Province [J]. Western Leather, 2016, 38 (14): 121-122.

[15] Lu Yanhong. Research on the Development Path of Tourism Industry in Zhangzhou from the Perspective of High-speed Railway Visitors' Perception [J]. Coastal Enterprises and Technology, 2018.

[16] Yao Lifen, Wang Xingrang, Ren $\mathrm{Na}$, et al. Satisfaction Research on Rural Tourism Toilets Based on IPA Evaluation [J]. Hebei Enterprise, 2018 (1): 40-42.

[17] Li Wenyong, Wang Wei, Tan Tonghui. Research on the Relationship between Recreation Experience, Satisfaction and Local Attachment in Cultural and Creative Tourism Destinations [J]. SAR Economics, 2018 (5).

[18] Pang Yulan, Wang Xin. Analysis of Satisfaction Evaluation of Scenic Culture Construction Based on Questionnaire Survey [J]. Northern Economy and Trade, 2019 (6).

[19] Lu Xinxin. Research on Tourism Public Service Based on Tourist Satisfaction_-Taking Sanya as an Example [J]. Modernization of Shopping Mall, 2016 (24): 126-127. 